\title{
PERANCANGAN GAME BEDUGUL FOREST DENGAN METODE PENGEMBANGAN MULTIMEDIA LUTHER-SUTOPO
}

\author{
Wahyu Untoro ${ }^{1}$, I Putu Satwika ${ }^{2}$, Anak Agung Ayu Putri Ardyanti ${ }^{3}$, Wawan Sujarwo ${ }^{4}$ \\ 1,2,3 Program Studi Teknik Informatika STMIK Primakara \\ wahyuuntoro54@gmail.com¹, satwika@primakara.ac.id², putri.ardyanti@primakara.ac.id³ \\ wawan.sujarwo@lipi.go.id ${ }^{4}$
}

\begin{abstract}
Abstrak
Game adalah salah satu cara yang dilakukan beberapa orang untuk merasakan kesenangan. Tidak hanya itu, game juga bermanfaat sebagai sarana untuk belajar. Game edukasi memiliki tujuan untuk dapat meningkatkan pemahamaan siswa agar tertarik belajar hal-hal baru, termasuk belajar mengenai pengenalan Budaya Bali ke masyarakat umum tanpa menghilangkan sisi edukasi sejarah. Museum Panca Yadnya adalah sebuah museum yang berada di kawasan Kebun Raya Eka Karya Bali. Menurut penelitian yang telah dilakukan sebelumnya, Kunjungan wisatawan tidak menentu ke objek wisata Kebun Raya Eka Karya. Oleh karena hal tersebut, peneliti merasa perlu untuk membuat sebuah game yang memperkenalkan museum Panca Yadnya kepada masyarakat umum. Dalam pembuatan game, salah satu metode yang digunakan adalah metode Luther-Sutopo dengan penambahan tahapan maintenance. Berdasarkan kombinasi metode perancangan game tersebut dibuatlah game Bedugul Forest yang mengangkat tema Museum Panca Yadnya Kebun Raya Eka Karya. Adapun setelah diuji kepada pengguna secara langsung, game Bedugul Forest mendapatkan penilaian rata-rata sangat baik dari semua aspek yang diujikan.
\end{abstract}

Kata Kunci: Bali, Bedugul Forest, Game Edukasi, Museum, Multimedia

\begin{abstract}
Game is one of the ways that several people do to experience joy. Not only that, but games also helpful as a tool to study. Game education has an objective to improve students understanding to learn new things, including learning about the introduction of Balinese culture to the public without removing the historical education side. Panca Yadnya Museum is a museum in the area of Eka Karya Botanical Garden in Bali. According to the research had been done before, tourist visits to Eka Karya Botanical Garden have been uncertain. Because of this matter, researchers fell necessary to create a game that introduces the Panca Yadnya Museum to the public. In creating the game, one of the methods used is the Luther-Sutopo method with the addition of the maintenance stage. Based on the combination of game design methods, the Bedugul Forest game has made which took up the theme of Panca Yadya Museum Eka Karya Botanical Garden. After tested to users directly, the Bedugul Forest game gets the average excellent judgment from all aspects that had tested.
\end{abstract}

Keywords: Bali, Bedugul Forest, Education Game, Museum, Multimedia 


\section{PENDAHULUAN}

Game adalah salah satu cara yang dilakukan beberapa orang untuk merasakan kesenangan. Orang akan merasa senang karena merasa memiliki dunianya sendiri. Di dalam game setiap pemain memiliki tujuan untuk dapat memenangkan game. Jikalau pun kemenangan tidak didapatkan, maka game dapat diulang kembali (Adams, 2009). Selain sebagai media bersenang-senang, game juga memiliki manfaat sebagai media edukatif dan disebut dengan game edukasi. Game edukasi memiliki tujuan untuk dapat meningkatkan pemahan siswa sehingga siswa akan tertarik belajar suatu hal baru (Novaliendry, 2013). Selain bagi siswa, game edukasi juga dapat memberikan hiburan dan dapat mengenalkan salah satu Budaya Bali ke masyarakat umum tanpa menghilangkan sisi edukasi sejarah (Putra, Wiranatha, \& Buana, 2015).

Dalam penelitian ini, penulis akan membuat sebuah game yang diberi nama Bedugul Forest. Game Bedugul Forest mengambil latar belakang Museum Panca Yadnya. Museum Panca Yadnya adalah sebuah museum yang berada di kawasan Kebun Raya Eka Karya Bali. Museum Panca Yadnya diresmikan pada bulan Juli 2018. Museum ini menyimpan artefak dan tumbuhan yang berhubungan dengan lima upacara dalam agama Hindu (Kebun Raya Bali LIPI, n.d.). Menurut penelitian yang telah dilakukan sebelumnya, didapati bahwa Kunjungan wisatawan tidak menentu ke objek wisata Kebun Raya Eka Karya (Purnama \& Ardyanti, 2017). Selain itu, saat melakukan observasi lapangan, museum Panca Yadnya tidak dibuka penuh untuk umum karena masih minimnya petugas yang dapat menjadi penjaga barang-barang di museum. Namun kedepannya, jika terdapat banyak pengunjung museum Panca Yadnya akan dibuka penuh untuk umum. Oleh karena hal tersebut, peneliti merasa perlu untuk membuat sebuah game yang memperkenalkan museum Panca Yadnya kepada masyarakat umum.

Dalam pembuatan game, salah satu metode yang dapat digunakan adalah metode Luther-Sutopo. Metode Luther-Sutopo adalah sebuah metode yang dikembangkan oleh Hadi Sutopo dengan memodifikasi metode multimedia development life cycle. Metode Luther-Sutopo dapat digunakan untuk membuat bermacam macam produk multimedia mulai dari film, video sampai dengan aplikasi multimedia atau game (Binanto, 2010). Metode pengembangan multimedia Luther-Sutopo yang terbagi menjadi 6 tahapan yaitu konsep, design, material collecting, assembly, testing dan distribusi. Dalam pembuatan game Bedugul Forest akan digunakan metode Luther-Sutopo sebagai metode utama. Namun disisi lain, Hidayat dan Astari menekankan bahwa maintenance adalah salah satu dari tahapan yang harus dilakukan pada game agar tahapan publishing game sukses dan berjalan lancar (Hidayat \& Astari, 2018). Sehingga dalam pembuatan game metode perancangan akan dikembangkan dengan penambahan tahapan maintenance kepada game.

\section{METODE PENELITIAN}

Metode penelitian merupakan langkah-langkah yang dikerjakan dan disusun secara sistematis untuk mendapatkan data yang valid dengan tujuan agar penelitian dapat ditemukan, dikembangkan serta dibuktikan untuk lebih lanjutnya dapat memecahkan 
suatu masalah. Dalam penelitian ini menggunakan pengembangan metode dari LutherSutopo dengan menambahkan metode dari Hidayat dan Astari yaitu maintenance.

\subsection{Objek Penelitian}

Objek yang digunakan untuk dilakukan dalam penelitian pengembangan metode LutherSutopo dalam pembuatan game edukasi Bedugul Forest adalah masyarakat Indonesia dengan rentang usia 15 sampai 31 tahun yang pernah mengunjungi Kebun Raya Eka Karya.

\subsection{Populasi Penelitian}

Populasi dalam penelitian pengembangan metode Luther-Sutopo dalam pembuatan game edukasi Bedugul Forest adalah masyarakat Bali dan wisatawan yang berasal dari Indonesia yang pernah berkunjung ke Bali.

\subsection{Sampel Penelitian}

Dalam penelitian ini digunakan teknik sampling yaitu teknik probability sampling dengan tipe simple random sampling. Tipe ini akan mengambil sampel masyarakat secara acak untuk setiap masyarakat umum ataupun wisatawan yang berasal dari Indonesia yang pernah berkunjung ke Kebun Raya Eka Karya. Untuk menentukan jumlah sampel dari penelitian, digunakan rumus yang dikemukakan Hadari Nawawi (Dr. Sandu Siyoto, SKM \& Nia Sari, S. Si, 2016).

$$
n \geq p q\left(\frac{z^{1 / 2} \alpha}{b}\right)^{2}
$$

Keterangan:

$\mathrm{n} \quad=$ ukuran sampel

$\mathrm{p} \quad=$ proporsi populasi presentase kelompok pertama

$\mathrm{q} \quad=$ proporsi sisa dalam populasi

$\mathrm{Z}^{1} / 2 \alpha$ = besarnya $\mathrm{Z}$ untuk $\alpha$ tertentu

$\mathrm{b} \quad=$ presentasi kemungkinan toleransi kesalahan

Pada perhitungan sampel untuk game Bedugul Forest, ditentukan beberapa nilai untuk menghitung sampel. Diketahui jumlah wisatawan domestik tahun 2017 sejumlah 8.735.633 orang(Badan Pusat Statistik Bali, 2018). Sedangkan penduduk Bali tahun 2017 diperkirakan sejumlah 4.246.500 orang(Badan Pusat Statistik Bali, n.d.). Untuk pengunjung Kebun Raya Eka Karya terdiri dari wisatawan yang berasal dari Indonesia dan penduduk lokal Bali berjumlah 384.064 pengunjung ("Jumlah pengunjung Kebun Raya LIPI tahun 2014-2017," 2017). Kemungkinan tingkat kekeliruan dalam penelitian ini adalah $5 \%$ sehingga $Z^{1} / 2 \alpha$ adalah 1.96 .

Dari data diatas, selanjutnya dimasukkan ke dalam rumus sebagai berikut. 
Diketahui:

pengunjung = pengunjung Kebun Raya Eka Karya $=384.064$

wisdom = wisatawan domestik $=8.735 .633$

penduduk $\quad=$ Penduduk Bali $=4.246 .500$

$p=\frac{\text { pengunjung }}{(\text { wisdom }+ \text { penduduk })} 100 \%$

$p=\frac{384.064}{(8.735 .633+4.246 .500)} 100 \%=3 \%=0.03$

$\mathrm{q} \quad=1-\mathrm{p}$

$$
=0.97
$$

$\mathrm{Z}^{1 / 2} \alpha=1,96$

b $\quad=5 \%=0.05$

$n \geq p q\left(\frac{z^{1 / 2} \alpha}{b}\right)^{2}$

$n \geq(0,03)(0,97)(1536,64)$

$n \geq 44.7$

Dalam penelitian ini digunakan minimal 45 orang masyarakat umum dan wisatawan yang berasal dari Indonesia dan pernah mengunjungi Kebun Raya Eka Karya dengan rentang usia 15 tahun sampai 31 tahun.

\subsection{Alur Pengembangan Game}

Alur Penelitian adalah langkah peneliti dalam melakukan penyusunan laporan penelitian. Alur penelitian ini mengambil langkah-langkah dari pengembangan multimedia Luther-Sutopo dengan ditambahkan tahapan maintenance. Tahapan maintenance penting karena dalam membuat game, salah satu yang menjadi kunci sukses dalam publishing game adalah memperbaiki fitur di dalam game secara berkala. hal ini dapat membuat pengguna bertahan menggunakan game. Untuk mempermudah penjelasan alur pengembangan game, alur digambarkan pada gambar 1 .

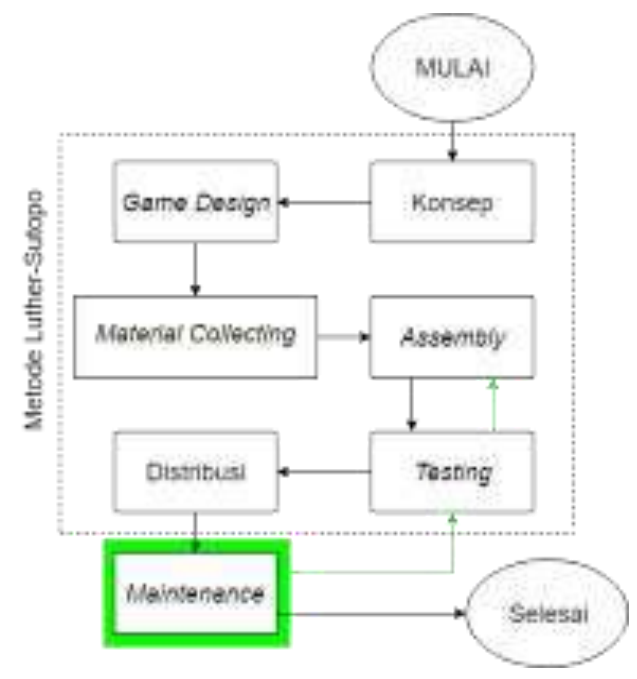

Gambar 1. Alur Pengembangan Game [Sumber: Dokuemtasi Wahyu,dkk] 


\subsubsection{Konsep}

Konsep merupakan dasar dari pengembangan sebuah produk. Di dalam konsep akan ditentukan tujuan dibuatnya aplikasi serta target pengguna yang akan disasar. Selain tujuan, dasar aturan dalam aplikasi juga ditentukan. Dasar aturan yang ditentukan dapat berupa ukuran aplikasi serta target pengguna aplikasi (Binanto, 2010). Pada tahapan ini dicari permasalahan yang ada di Museum Panca Yadnya Kebun Raya Eka Karya melalui pengumpulan data. Pengumpulan data yang digunakan adalah studi literatur, wawancara serta observasi. Adapun dari pengumpulan data didapatkan bahwa salah satu permasalahan yang ada adalah kurangnya pengunjung yang mengunjungi museum. Selanjutnya dari konsep akan dibuatkan beberapa game design yang dapat dipilih dari pihak museum.

\subsubsection{Game Design}

Tahapan Game Design adalah tahapan untuk mendesign spesifikasi dari produk yang dibuat. Spesifikasi mencangkup arsitektur product, style, tampilan dan material untuk produk. Pada tahapan design biasanya akan digunakan storyboard untuk menampilkan semua tahapan dan mendeskripsikan setiap scene. Storyboard akan dijadikan sebagai pedoman utama dalam membuat produk, untuk itu storyboard harus jelas dan detail agar tidak terjadi kesalahpahaman pada team (Binanto, 2010). Pada tahapan game design dibuat detail dari aplikasi yang telah dikonsepkan. Game design dikirim kepada pihak museum, dari beberapa game design akan dipilih satu untuk selanjutnya dibuat menjadi program. Tahap selanjutnya adalah mengumpulkan bahan penunjang game serta mengimplementasikannya menjadi sebuah game yang dapat dimainkan.

\subsubsection{Material Collecting}

Tahapan material collecting adalah tahapan untuk membuat serta mengumpulkan material-material yang akan digunakan dalam produk. Material tersebut dapat berupa gambar, suara, animasi ataupun materi pendukung produk lainnya yang dapat diperoleh secara gratis ataupun membeli. Semua material yang dikumpulkan berdasarkan yang telah ditetapkan pada tahapan design. Tahapan material collecting dapat dilakukan bersamaan dengan tahapan assembly (Binanto, 2010). Material Collecting merupakan tahapan dalam mengumpulkan seluruh material berupa suara, video, gambar ataupun materi-materi terkait yang akan digunakan dalam pembuatan game edukasi Bedugul Forest. Proses material collecting akan dilakukan bersamaan dengan proses assembly.

\subsubsection{Assembly}

Tahapan assembly merupakan tahapan dimana semua material digabungkan berdasarkan tahapan yang ada di dalam storyboard. Tahapan assembly mencangkup pembuatan illustrasi, pembuatan audio serta pemrogramman (Binanto, 2010). Assembly atau prototyping adalah pembuatan dan penggabungan seluruh material menjadi sebuah game yang utuh. Dalam pembuatan material gambar digunakan software Adobe Photoshop serta Adobe Illustrator dalam pembuatan gambar. Untuk animasi menggunakan software Spriter. Untuk audio menggunakan software Adobe Audition. Dalam penggabungan elemen menjadi game yang utuh penulis menggunakan game engine Construct 2. 


\subsubsection{Testing}

Tahapan selanjutnya setelah assembly adalah tahapan testing. Pada tahapan testing produk diuji apakah sudah layak untuk dapat didistribusikan kepada pengguna. Pengujian dilakukan dengan tujuan untuk mengetahui produk berjalan sesuai dengan rancangan pada tahapan design (Binanto, 2010). Tahapan testing merupakan tahapan yang penting untuk dilakukan untuk menghindari bug atau kesalahan sistem pada game. Pada testing menggunakan metode pengujian Blackbox untuk mengetahui hasil akhir dari game yang telah dibuat. Jika ditemukan sebuah bug maka akan kembali lagi ke tahapan assembly.

\subsubsection{Distribusi}

Selanjutnya setelah game selesai dibuat, tahap berikutnya adalah distribusi. Tahapan distribusi adalah tahapan untuk membuat master file. Master file didistribusikan kepada user dengan dokumentasi produk dan user manual (Binanto, 2010). Tahap distribusi adalah tahapan untuk memberikan akses kepada pengguna untuk memakai game yang telah dibuat. Pada tahap distribusi juga dilakukan pemasaran terhadap aplikasi yang telah dibuat.

\subsubsection{Maintenance}

Setelah game disebarluaskan kepada pengguna ada beberapa kunci sukses yaitu DevOps atau pembaruan konten secara regular. Analysis-Driven decision, semua update pada game akan mempengaruhi data pengguna. Marketing, melakukan pra-release ke media untuk memperkenalkan game yang dibuat. Serta retensi, memperbarui game sesuai Analisa pengguna dan evaluasi keberhasilan dan kekurangan secara berkala (Hidayat \& Astari, 2018). Tahapan terakhir adalah maintenance, maintenance adalah tahapan perawatan terhadap game yang telah didistribusikan. Pada tahapan maintenance juga dilakukan pengecekan statistik mulai dari jumlah downloader hingga laporan mengenai berapa sering game crash. Jika banyak terjadi crash maka game harus dicek kembali dan masuk ke tahap assembly. Selain itu pada tahapan maintenance juga disebarkan kuesioner kepada masyarakat setelah mencoba game edukasi Bedugul Forest untuk mengetahui tingkat kepuasan masyarakat terhadap grafis, gameplay serta untuk mendapatkan saran untuk pengembangan game ke depannya. Tahapan ini penting sebagai perencanaan pengembangan game ini ke depannya, apakah perlu adanya perbaikan untuk kenyamanan user dalam bermain.

\section{HASIL DAN PEMBAHASAN}

\subsection{Tahapan Konsep}

Pada tahapan konsep dilakukan observasi dan wawancara terhadap Bapak Dr. Wawan Sujarwo selaku Kepala Humas Museum Panca Yadnya Kebun Raya Bali yang berlokasi di Museum Panca Yadnya Kebun Raya Eka Karya. Dari observasi dan wawancara tersebut dihasilkan bahwa kunjungan di Museum Panca Yadnya Kebun Raya Eka Karya hampir tidak ada dikarenakan museum belum dibuka untuk umum. Karena hal tersebut maka dikonsepkan sebuah game yang akan diperuntukkan sebagai media untuk memperkenalkan Kebun Raya Eka Karya kepada masyarakat. Game ini nantinya dapat berada di dalam sistem yang terintegrasi yang didalamnya terdapat sistem informasi 
artefak, sistem informasi tanaman obat dan game-game pengenalan lingkungan Kebun Raya Eka Karya Bedugul.

\subsection{Tahapan Design}

Pada tahapan game design telah dibuat dua game design dokumen yang dipresentasikan kepada Bapak Dr. Wawan Sujarwo selaku Kepala Humas dari Kebun Raya Eka Karya. Dari presentasi game design dokumen tersebut dipilih game design document yang berjudul Bedugul Forest. Game Design Document dapat dilihat pada tabel 1.

Tabel 1. Game Design Document

[Sumber: Dokumentasi Wahyu, dkk]

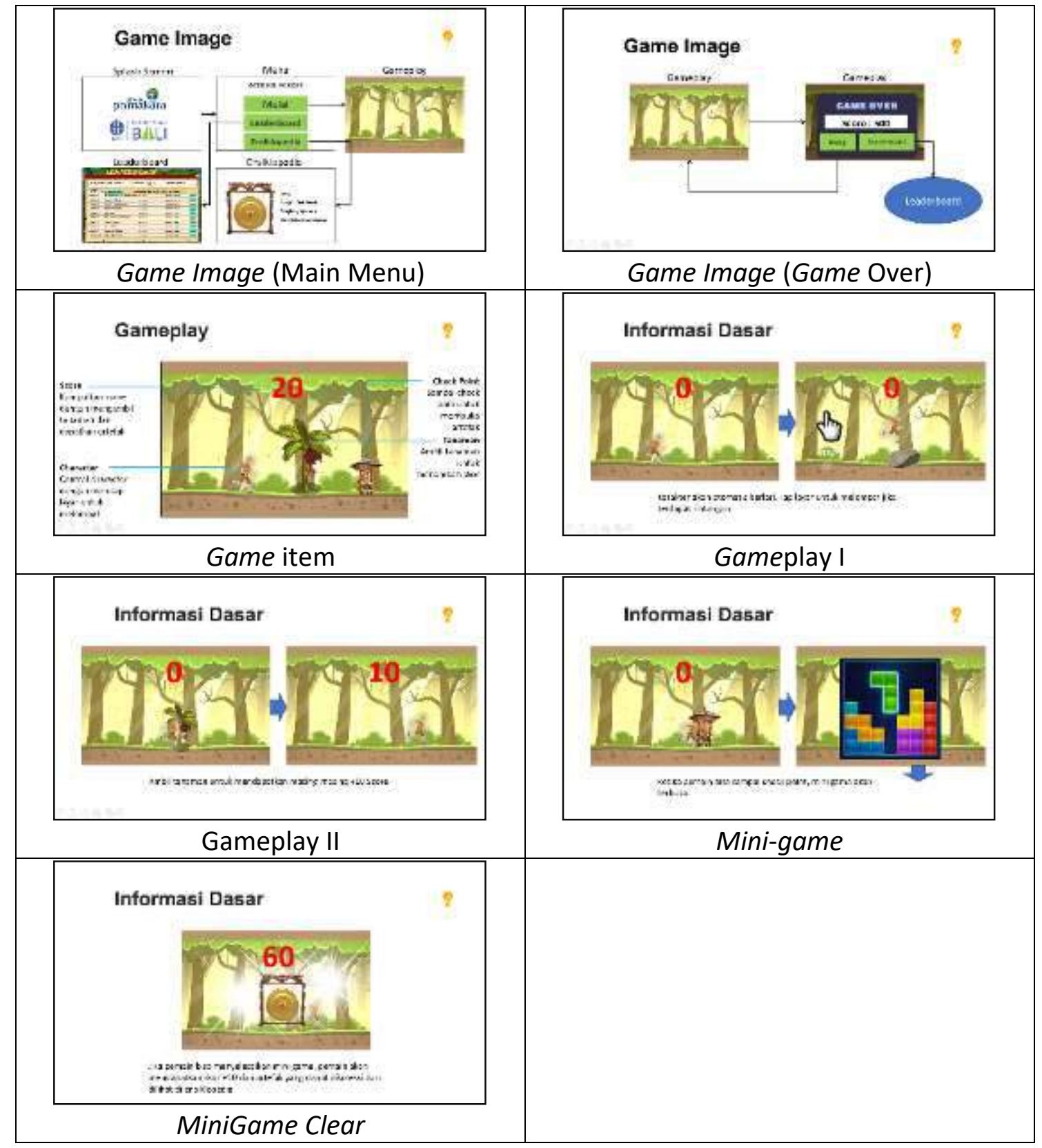




\subsection{Tahapan Material Collecting}

Pada tahapan ini dikumpulkan material yang akan digunakan dalam pembuatan game. Pada tahapan ini dilakukan juga pengambilan gambar artefak ke Museum Panca Yadnya di Kebun Raya Eka Karya. Pada tahapan ini dapat dilakukan design terhadap asset yang digunakan dalam game bersamaan dengan tahapan assembly.

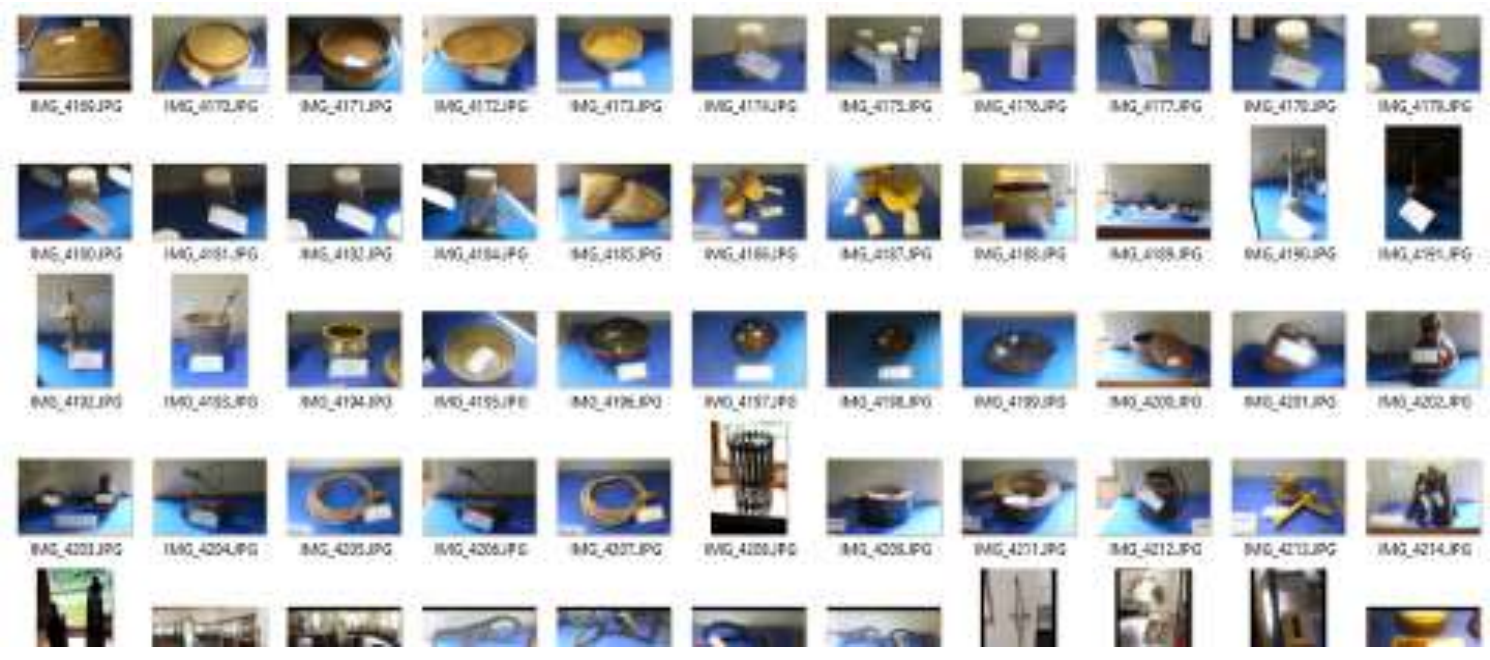

Gambar 2. Hasil Material Collecting

[Sumber: Dokumentasi Wahyu, dkk]

\subsection{Tahapan Assembly}

Pada tahapan assembly semua material akan digabungkan untuk menjadi sebuah program. Pada tahapan ini penulis menggunakan game engine Construct 2 untuk menggabungkannya menjadi sebuah game yang dapat dimainkan. Contruct 2 merupakan sebuah game engine yang menghasilkan project akhir HTML5. File HTML5 tersebut selanjutnya diubah dengan menggunakan cocoon.io untuk mendapatkan file APK yang dapat di-install pada perangkat android.

\subsection{Tahapan Testing}

Setelah tahapan assembly selesai, tahapan pengujian akan dimulai dengan Blackbox testing. Blackbox testing dibagi menjadi dua fase yaitu fase pertama menguji aplikasi kepada pihak-pihak yang mengetahui tentang tujuan dan fungsi dari game yang dibuat. Sedangkan fase kedua dilakukan kepada user umum, yang akan memainkan game ini nantinya. Fase kedua akan dilakukan setelah pengujian fase pertama selesai dan hasil revisi yang dibuat disetujui oleh penguji. Berikut adalah hasil dari Blackbox testing fase pertama dan kedua. 
Tabel 2. Blackbox Testing Fase I

[Sumber: Dokumentasi Wahyu, dkk]

\begin{tabular}{|c|c|}
\hline Sebelum Testing & Hasil Revisi \\
\hline \multicolumn{2}{|c|}{ Game Story } \\
\hline $\begin{array}{l}\text { Bedugul Forest adalah sebuah game } \\
\text { edukasi yang berlatar belakang } \\
\text { seorang arkeolog yang berpetualang } \\
\text { di Hutan Bedugul untuk menemukan } \\
\text { artefak-artefak tersembunyi. Dalam } \\
\text { mengumpulkan artefak, arkeolog } \\
\text { akan berlari sambil mengumpulkan } \\
\text { tanaman-tanaman upacara yang } \\
\text { ada. }\end{array}$ & $\begin{array}{l}\text { Disuatu wilayah di Bali Dwipa, terdapat } \\
\text { sebuah kerajaan yang dipimpin oleh } \\
\text { seorang raja yang sombong dan rakus. } \\
\text { Pendeta ini pun mendatangi raja dan } \\
\text { memberinya nasehat, namun raja } \\
\text { malah marah dan memerintahkan } \\
\text { pasukannya untuk membunuh pendeta } \\
\text { tersebut. Pendeta tersebut pun } \\
\text { mengutuk raja menjadi monyet dan } \\
\text { harus mengumpulkan seluruh benda } \\
\text { keramat pendeta untuk dapat berubah } \\
\text { kembali menjadi manusia. }\end{array}$ \\
\hline \multicolumn{2}{|c|}{ Opening/Intro Game } \\
\hline \multicolumn{2}{|l|}{ Tidak Ada } \\
\hline \multicolumn{2}{|c|}{ Gameplay Utama } \\
\hline & $4=$ \\
\hline \multicolumn{2}{|c|}{ Gameplay Mini Game } \\
\hline 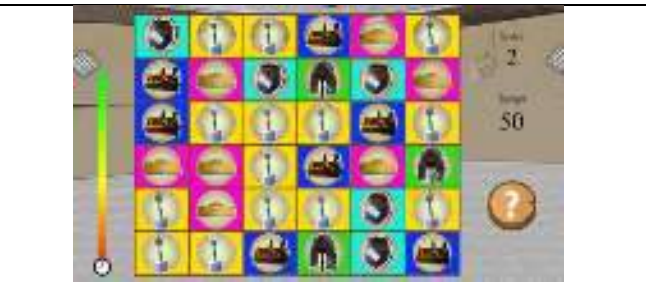 & $2 \times 7$ \\
\hline \multicolumn{2}{|c|}{ Gameplay Mini Game } \\
\hline
\end{tabular}




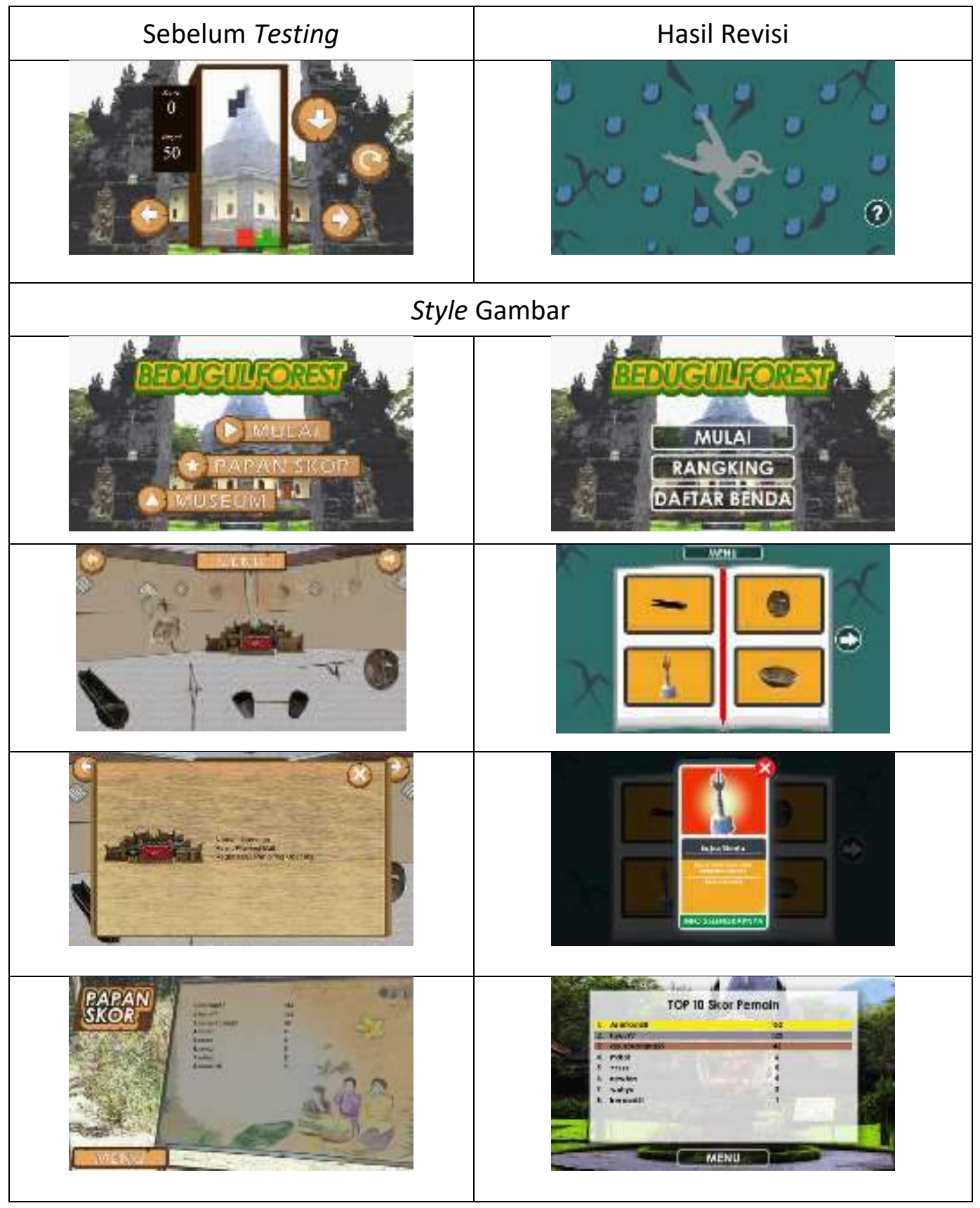

Tabel 3. Blackbox Testing Fase II

[Sumber: Dokumentasi Wahyu, dkk]

\begin{tabular}{|l|l|}
\hline \multicolumn{1}{|c|}{ Bagian Pengujian } & \multicolumn{1}{c|}{ Hasil Revisi } \\
\hline Gameplay Utama & Rintangan awal terlalu cepat muncul. \\
\hline Gameplay Utama & $\begin{array}{l}\text { Energy terlalu cepat habis dan item pisang } \\
\text { terlalu lama muncul. }\end{array}$ \\
\hline Game Over Menu & Tombol leaderboard tidak berfungsi. \\
\hline
\end{tabular}

Pengujian validitas dan reliabilitas akan dilakukan setelah tahapan distribusi. Pada pengujian ini user dari game akan diberikan kuesioner dalam bentuk Google Form. Menurut Korhonen, kuisioner digunakan untuk menguji aspek playability pada 
permainan. Aspek playlability terdiri dari 3 faktor yaitu Gameplay, usability dan mobility (Rifai, 2015). Di penelitian lain ditambahkan juga faktor audio yang diujikan kepada user (Andriyanto, 2016).

Berdasarkan penelitian sebelumnya yang telah dilakukan Rifai dengan pertimbangan dari Korhonen, serta penelitian Andriyanto. Serta mempertimbangkan penelitian dari Dewi (Ghea Putri Fatma Dewi, 2012) maka dibuatlah sebuah kuesioner yang terdapat pada tabel 4. Dari pertanyaan kuesioner yang telah disipakan akan diuji menggunakan SPSS untuk mengetahui apakah kuesioner valid dan reliabel. Kuesioner dinyatakan valid jika $\mathrm{R}$ hitung $>\mathrm{R}$ tabel. $\mathrm{R}$ hitung didapatkan dari perhitungan SPSS sedangkan $\mathrm{R}$ table menggunakan acuan $R$ Tabel : 0,632.

Setelah dilakukan uji validitas selanjutnya dari pertanyaan yang valid dilakukan pengujian reliabilitas menggunakan IBM SPSS dan mendapatkan hasil 0.6319. hasil tersebut lebih kecil daripada nilai Alpha Cronbach's yaitu 0.962. Maka kuesioner tersebut dinyatakan valid dan reliabel.

Setelah game Bedugul Forest berhasil dibuat menggunakan pengembangan metode Luther-Sutopo, selanjutnya akan dihitung penilaian user terhadap game Bedugul Forest. Untuk menghitung kuesioner dengan skala likert, setiap butir jawaban akan dikali tingkat persetujuan. Setelah nilai setiap pengguna dikali, lalu dijumlahkan dan di klasifikasikan dalam gambar 3 dan hasilnya seperti pada tabel 4.

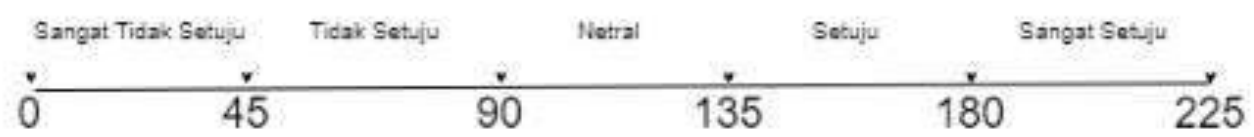

Gambar 3. Diagram Penentuan Respon Pengguna

[Sumber: Dokumentasi Wahyu, dkk]

Tabel 4. Hasil Kuesioner Penilaian User

[Sumber: Dokumentasi Wahyu, dkk]

\begin{tabular}{|c|c|c|c|}
\hline No & Pernyataan & Nilai & Hasil \\
\hline \multicolumn{4}{|c|}{ Faktor Usability } \\
\hline 1 & $\begin{array}{l}\text { Tata letak layar efisien dan visual yang ditampilkan } \\
\text { menyenangkan }\end{array}$ & 187 & Sangat Setuju \\
\hline 2 & Indikator dan simbol yang ada pada game terlihat dengan jelas & 187 & Sangat Setuju \\
\hline 3 & Istilah dalam game mudah dimengerti & 188 & Sangat Setuju \\
\hline 4 & Icon tombol konsisten dan sesuai aturan & 195 & Sangat Setuju \\
\hline 5 & Kontrol mudah dipahami & 195 & Sangat Setuju \\
\hline 6 & Game memberikan umpan balik pada tindakan pemain & 188 & Sangat Setuju \\
\hline 7 & Game dapat terjadi error permanen dan harus merestart game & 134 & Netral \\
\hline 8 & $\begin{array}{l}\text { Pemain tidak perlu menghafal hal-hal yang tidak penting dalam } \\
\text { game }\end{array}$ & 186 & Sangat Setuju \\
\hline
\end{tabular}




\begin{tabular}{|c|c|c|c|}
\hline No & Pernyataan & Nilai & Hasil \\
\hline 9 & Game disertai petunjuk/bantuan & 196 & Sangat Setuju \\
\hline 10 & Karakter dalam game menarik & 159 & Setuju \\
\hline 11 & Pemain mendapatkan pengetahuan baru dari game & 192 & Sangat Setuju \\
\hline & Rata-rata & 182.4 & Sangat Setuju \\
\hline \multicolumn{4}{|c|}{ Faktor Mobility } \\
\hline 12 & Loading game dapat dimulai dengan cepat & 192 & Sangat Setuju \\
\hline 13 & Game dapat dimainkan kapan saja & 204 & Sangat Setuju \\
\hline 14 & $\begin{array}{l}\text { Game tidak terganggu dengan notifikasi seperti sms masuk } \\
\text { ataupun telepon }\end{array}$ & 188 & Sangat Setuju \\
\hline & Rata-rata & 194.7 & Sangat Setuju \\
\hline \multicolumn{4}{|c|}{ Faktor Gameplay } \\
\hline 15 & $\begin{array}{l}\text { Game dapat mengenalkan Museum Panca Yadnya Kebun Raya } \\
\text { Eka Karya Bedugul Bali }\end{array}$ & 190 & Sangat Setuju \\
\hline 16 & Pemain dapat melihat progress dari permainan sebelumnya & 194 & Sangat Setuju \\
\hline 17 & Pemain mendapatkan hadiah yang bermakna & 176 & Setuju \\
\hline 18 & Pemain yang mengkontrol semua dalam game & 192 & Sangat Setuju \\
\hline 19 & Tantangan, strategi dan kecepatan seimbang & 188 & Sangat Setuju \\
\hline 20 & $\begin{array}{l}\text { Ketika pertama bermain, pemain merasa ingin terus bermain } \\
\text { lagi }\end{array}$ & 183 & Sangat Setuju \\
\hline 21 & Alur cerita mendukung permainan & 189 & Sangat Setuju \\
\hline 22 & Tidak ada tugas berulang yang membosankan & 171 & Setuju \\
\hline 23 & Pemain dapat mengekspresikan diri & 174 & Setuju \\
\hline 24 & Game mendukung cara bermain yang beragam & 181 & Sangat Setuju \\
\hline 25 & Game tidak stagnan atau membosankan & 175 & Setuju \\
\hline 26 & Game konsisten & 195 & Sangat Setuju \\
\hline 27 & $\begin{array}{l}\text { Dalam game, setiap objek yang berbeda memiliki tujuan yang } \\
\text { berbeda }\end{array}$ & 198 & Sangat Setuju \\
\hline 28 & Pemain tidak kelelahan saat bermain game & 188 & Sangat Setuju \\
\hline & Rata-rata & 199.5 & Sangat Setuju \\
\hline \multicolumn{4}{|c|}{ Faktor Audio } \\
\hline 29 & Latar musik bagus dan sesuai & 194 & Sangat Setuju \\
\hline 30 & Suara dan hukuman jelas menarik & 193 & Sangat Setuju \\
\hline \multicolumn{2}{|r|}{ Rata-rata } & 193.5 & Sangat Setuju \\
\hline
\end{tabular}

\subsection{Tahapan Distribusi}

Setelah Blackbox testing selesai dan tidak ada bug system. Pada tahapan distribusi game akan diupload di Google Playstore. Setelah game diupload tahapan akan dilanjutkan dengan pengujian validitas dan reliabilitas untuk menguji kuesioner dan mendapatkan penilaian dari user. 


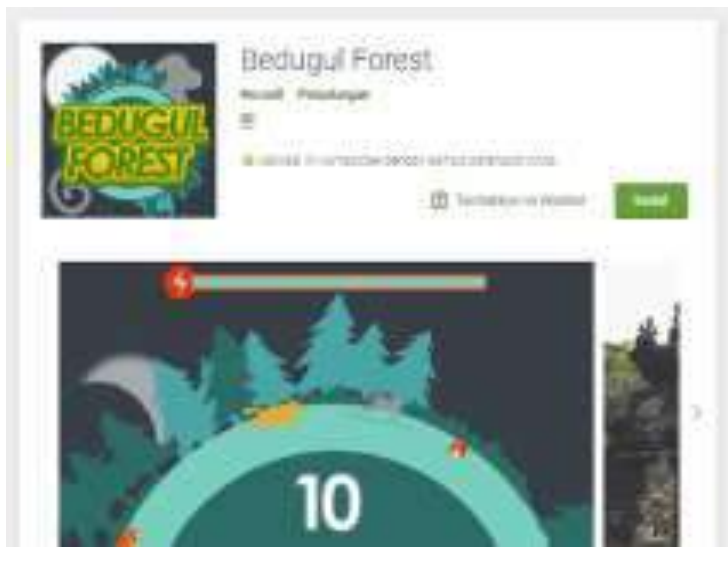

Gambar 4. Bedugul Forest di Google Playstore [Sumber: Dokumentasi Wahyu, dkk]

\subsection{Tahapan Maintenance}

Setelah game diupload melalui Google Playstore, tahapan selanjutnya adalah tahapan maintenance. Tahapan maintenance ini bersifat optional sesuai dengan kebutuhan. Maintenance dapat dilakukan ketika game sudah didistribusikan melalui Google Playstore terdapat masalah yang ditemukan user. Hingga saat jurnal ini dibuat, tahapan maintenance belum dilakukan karena tidak ditemukan masalah-masalah yang dapat mengganggu pemain memainkan game.

Tahapan maintenance dapat terjadi karena perbedaan resolusi layar, tipe dan spesifikasi smartphone yang berbeda sehingga menimbulkan perbedaan tampilan ataupun performa dari yang telah diuji oleh Peneliti. Per tanggal, 19 Januari 2019 saja terdapat 4007 jenis smartphone dari berbagai model dan merk serta produsen yang berbeda (google, n.d.). Dengan ada banyaknya model smartphone, jika kedepannya muncul resolusi layar baru atau spesifikasi-spesifikasi baru, diharapkan peneliti dapat melakukan maintenance kepada aplikasi yang telah di distribusikan.

Selain karena adanya update dari smartphone, laporan crash aplikasi dari pengguna juga menjadi bahan pertimbangan dalam melakukan maintenance. Aplikasi yang crash dari pengguna dapat dilihat pada halaman dashboard Google Playstore.

\section{KESIMPULAN}

Game edukasi Bedugul Forest dapat dibuat menggunakan metode pengembangan multimedia Luther-Sutopo ditambahkan dengan tahapan maintenance. Pembuatan game tersebut digambarkan pada gambar 5. Tahapan pembuatan game akan dimulai dari konsep, yang dilanjutkan dengan game design. Setelah game design disetujui semua pihak yang berwenang, selanjutnya adalah pembuatan material yang akan dimasukkan di dalam game, tahapan ini akan berbarengan dengan tahapan developing agar asset yang dibuat dapat digunakan seluruhnya serta saat proses developing terbayang hasil akhir game. Selanjutnya setelah proses developing selesai akan dilanjutkan dengan proses pengujian, jika saat proses pengujian ditemukan kegagalan atau yang disebut dengan bug, maka akan kembali ke tahap developing dan material collecting, bisa juga kembali ke tahapan game design jika memang harus ada kondisi 
yang ada pada game design tidak sesuai dengan hasil akhir yang diinginkan. Setelah tahapan pengujian selesai, barulah game dapat dilakukan distribusi ke pengguna. Proses terakhir adalah maintenance, proses maintenance bersifat optional ketika game telah di distribusikan. Penyebab dari maintenance dapat dilakukan adalah jika munculnya device baru ataupun crash report yang dilaporkan pengguna.

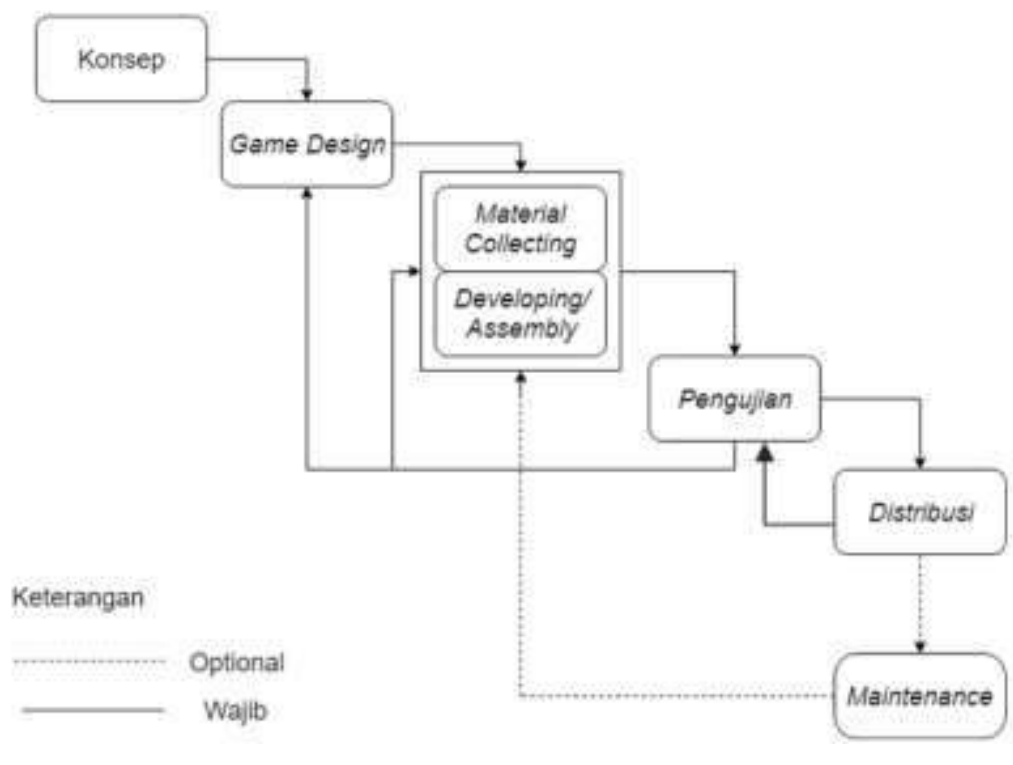

Gambar 5. Alur Pembuatan Game Bedugul Forest

[Sumber: Dokumentasi Wahyu, dkk]

Dari hasil implementasi game edukasi Bedugul Forest, didapatkan tanggapan dari pengguna berupa pernyataan untuk faktor usability, mobility, gameplay serta audio user sangat setuju.

\section{DAFTAR PUSTAKA}

Adams, E. (2009). Fundamentals of Game Design (2nd ed.). Retrieved from http://gen.lib.rus.ec/book/index.php?md5=b3cd92a69cf4997b7beb271b5338 $611 \mathrm{e}$

Andriyanto, I. (2016). Game Edukasi Pengenalan Rambu-Rambu Lalu Lintas. Universitas Muhammadiyah Surakarta, 1.

Badan Pusat Statistik Bali. (n.d.). Proyeksi Penduduk Provinsi Bali Menurut Kabupaten/Kota dan Jenis Kelamin, 2011-2020. Retrieved from https://bali.bps.go.id/dynamictable/2016/05/13/19/proyeksi-pendudukprovinsi-bali-menurut-kabupaten-kota-tahun-2011-2020-ribu-jiwa-.html

Badan Pusat Statistik Bali. (2018). Kunjungan Wisatawan Domestik ke Bali per Bulan, 2004-2017. https://bali.bps.go.id/statictable/2018/02/09/29/kunjungan-wisatawandomestik-ke-bali-per-bulan-2004-2017.html

Binanto, I. (2010). Multimedia Digital - Dasar Teori dan Pengembangannya. Penerbit Andi.

Dr. Sandu Siyoto, SKM, M. K., \& Nia Sari, S. Si, M. K. (2016). Aplikasi Dan Teknik Survey Bidang Kesehatan. Lliterasi Media. https://doi.org/10.1145/3132847.3132886 
Ghea Putri Fatma Dewi. (2012). Pengembangan Game Edukasi Pengenalan Nama Hewan Dalam Bahasa Inggris Sebagai Media Pembelajaran Siswa SD Berbasis Macromedia Flash. Skripsi.

google. (n.d.). Android Enterprise Solutions Directory - Devices. Retrieved from https://androidenterprisepartners.withgoogle.com./devices/

Hidayat, A., \& Astari, R. W. (2018). Menjadi Game Developer Expert. Dicoding.

Jumlah pengunjung Kebun Raya LIPI tahun 2014-2017. (2017). Retrieved from krbogor.lipi.go.id/id/download/unduh_berkas/72.html

Kebun Raya Bali LIPI. (n.d.). Kebun Raya Bali LIPI Buka Museum dan Taman PancaYadnya. Retrieved from lipi.go.id website: http://lipi.go.id/berita/kebun-raya-bali-lipibuka-museum-dan-taman-pancayadnya/20901

Novaliendry, D. (2013). Aplikasi Game Geografi Berbasis Multimedia Interaktif (Studi Kasus Siswa Kelas IX SMPN Rao). Jurnal Teknologi Informasi Dan Pendidikan.

Purnama, I. N., \& Ardyanti, A. A. A. P. (2017). PERAMALAN KUNJUNGAN WISATAWAN DI OBYEK WISATA BEDUGUL MENGGUNAKAN ALGORITMA FUZZY TIME SERIES. SMARTICS Journal, 3(2), 55-58.

Putra, I. D. M. Y. A., Wiranatha, A. A. K. A. C., \& Buana, P. W. (2015). Rancang Bangun Game Tapel Bali Pada Platform Android. Lontar Komputer.

Rifai, W. A. (2015). Pengembangan Game Edukasi Lingkungan Berbasis Android. Evolution, 1-14. https://doi.org/10.1126/science.aaf2941 